\title{
The influence of antero-posterior dentoskeletal pattern on the value of nasal soft tissue angles: a cephalometric study
}

\author{
T. Perović1 ${ }^{\circledR}$, Z. Blažej', I. Jovanović ${ }^{2}$ \\ ${ }^{1}$ Department for Orthodontics and Dentofacial Orthopaedics, Dental Clinic, Niš, Serbia \\ ${ }^{2}$ Department for Anatomy, Faculty of Medicine, University of Niš, Serbia
}

[Received: 1 June 2020; Accepted: 25 July 2020; Early publication date: 7 August 2020]

\begin{abstract}
Background: The aim of this study was to examine the influence of sagittal dentoskeletal pattern on the value of profile nasal soft tissue angles and estimate the significance of examined differences for each angle.

Materials and methods: Lateral cephalograms were used to examine the nasofrontal angle, nasofacial angle, nasal tip angle, and nasolabial angle of 120 adult Caucasian subjects (60 male and 60 female) from the central Balkan area. Subjects were divided into four groups according to the ANB angle and incisors inclination: class I as the control group, class II division 1, class II division 2 and class III.

Results: By evaluating the influence of sagittal dentoskeletal relationships on the values of examined angles, significant differences were found among subjects with class I and class III/2 ( $p=0.028)$, so as class III ( $p=0.002)$ for nasal tip angle. The nasofacial angle was found to differ among subjects with class I and class II/1 $(p=0.002)$, so as class III $(p=0.001)$.

Conclusions: Different dentoskeletal patterns have significant influence on values of the nasal tip angle and nasofacial angle, and don't have influence on the values of the nasofrontal and nasolabial angle. (Folia Morphol 2021; 80, 3: 657-664)
\end{abstract}

Key words: cephalometry, nose, dentoskeletal pattern

\section{INTRODUCTION}

The nose is central and most prominent part of the middle segment of the face, which is crucial for assessing facial harmony and attractiveness. The nasal pyramid plays a notable cosmetic role in the appearance of the whole face; providing harmony and balance to the face [22]. This segment as well as shape of the nose represents a "signature" indicating ethnicity, race, age, and gender $[18,19$, $22,23,31,32]$. Farkash was the first who began to apply selective anthropometric parameters that later researchers standardised and created "ideal nose" (cited by Lazovic [15]). Some of the shapes are purely racial-specific [22], so as angles that nose create with the nearby profile contours [33].

Are changes in the nasal profile angles correlated with different antero-posterior dentofacial pattern and to what extent? Since the midfacial segment and nose form the nasomaxillary complex, each antero-posterior jaw discrepancy is expected to influence the profile angles of this facial segment. Contours of the facial soft tissue differ from the contours of basic skeletal structures in certain areas, especially in the nasal third of the profile $[12,24,28,29]$. Therefore, 


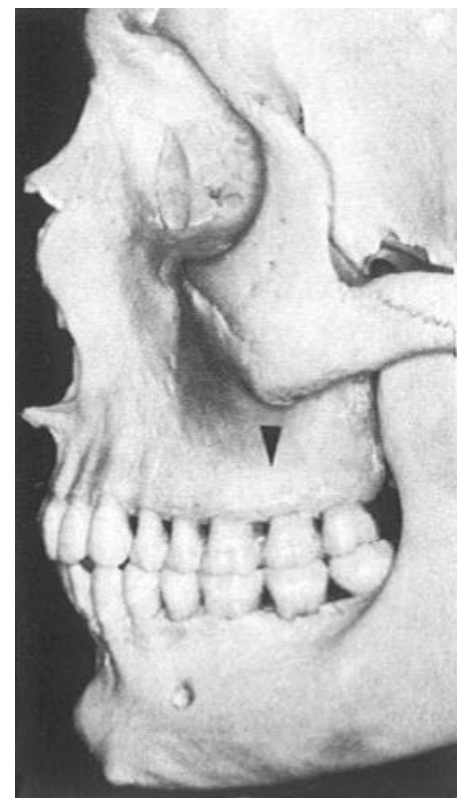

Figure 1. Skull with class I dentoskeletal pattern (source [26]).

facial profile angles are influenced by composite effect of skeletal and soft tissue profile. This fact indicates a possibility of difficult facial reconstruction based on the skull, because nose can have any shape. Likewise, angles that nose makes with nearby facial components can have any value inside the range of variations (racial, age and gender).

Dentoskeletal patterns highly influence the facial profile and facial aesthetics [24], especially the lower part of the face profile. However, some of the dentoskeletal patterns can imply a certain shape of the nose [23].

According to angle, class I dentoskeletal pattern is usually related to normal anteroposterior jaw relationship (Fig. 1), the straight profile and pleasant face.

Class II division 1 pattern present retroposition of the lower jaw in relation to the upper jaw (Fig. 2) and indicates a convex profile with the chin set posterior, therefore the dominant nose.

Class II division 2 pattern indicates a convex profile with characteristically emphasized tip of the nose and chin, having the tendency of mutual convergency (Fig. 3) [23]. This specific facial profile morphotype exists due to retropositioned dentoalveolar segment.

Class III pattern indicates overdeveloped lower jaw (Fig. 4) that is dominant in relation to other facial features (nose, forehead, lips). Persons with class III have a concave profile. This pattern is considered the least aesthetic [2, 24].

The aim of this study is to determine the values of facial profile angles of the midfacial (nasal) segment

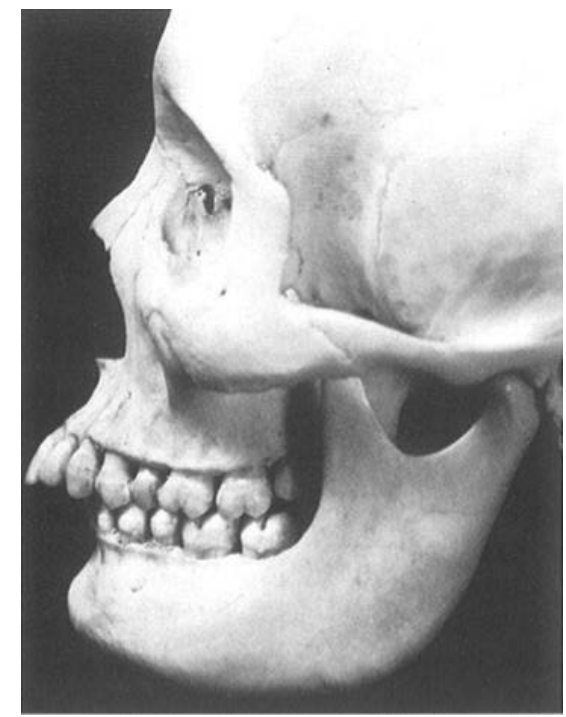

Figure 2. Skull with class II division 1 dentoskeletal pattern (source [26]).

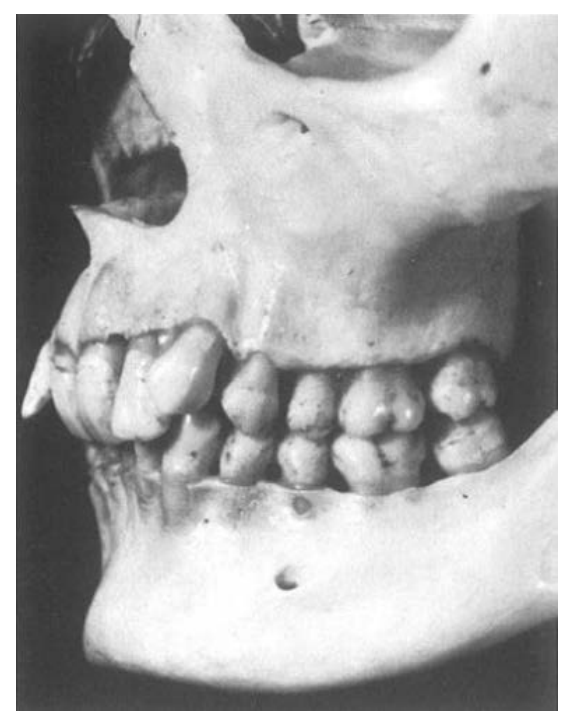

Figure 3. Skull with class II division 2 dentoskeletal pattern (source [26]).

in subjects with class I, class II division 1, class II division 2, and class III, in order to, examine, in this way, the influence of dentoskeletal pattern on the value of angular profile parameters of the nose region, as well as to examine the significance of the established variations for each angle individually.

\section{MATERIALS AND METHODS}

The study was conducted at the Faculty of Medicine, Niš, Serbia. Before the commencement of the study, each volunteer gave an informed consent as to the purpose and nature of the study. All work was per- 


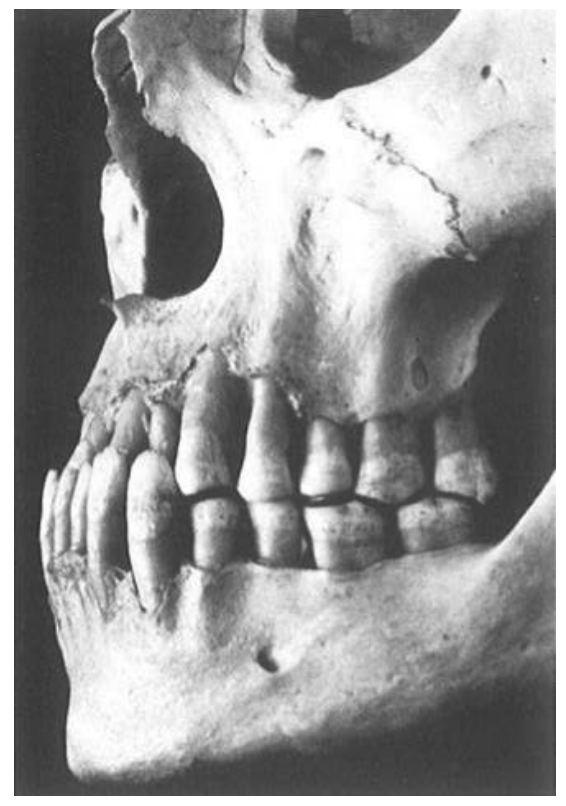

Figure 4. Skull with class III dentoskeletal pattern (source [26]).

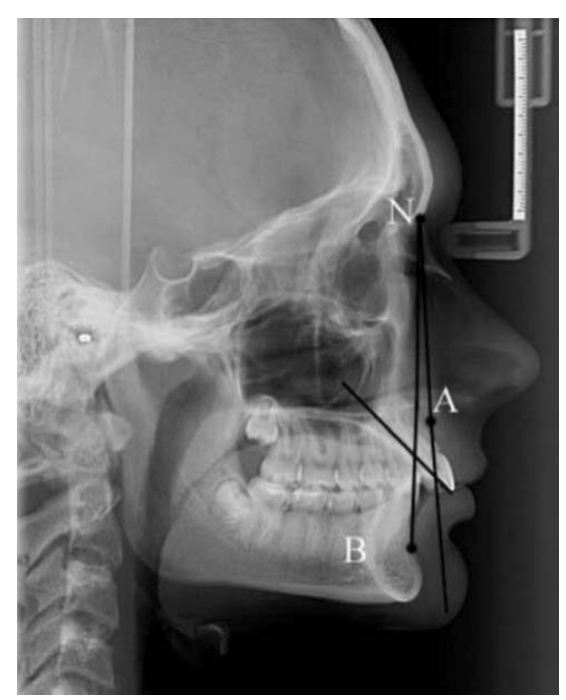

Figure 5. The cephalometric ANB angle and the angle of inclination of upper incisors.

formed in accordance with the Declaration of Helsinki and was approved by the Faculty's Ethics Committee (General project title of Clinical and Experimental Examination of the Stomatognathic System and Modern Therapeutic Procedures, Project Number 11, March $8^{\text {th }}, 2017$, Niš, Republic of Serbia).

This study included the examination and the analyses of cephalometric radiography data (lateral cephalograms) obtained from the profile angles of 120 adult Caucasian subjects (60 male and 60 female) from the central Balkan area (Serbia). The cephalograms were taken from the archives of the subjects. Lateral cephalograms were recorded during the routine diagnostic procedures for subjects who were examined at the Department of Dentofacial Orthopaedics at the Clinic of Dentistry in Niš, aged 18-30 years, and who underwent orthodontic therapy for the first time. The subjects with a history of trauma, craniofacial anomalies, cleft lip and palate, and previous orthodontic, prosthetic or orthognathic treatment were excluded from the study. Cephalometric radiographs of the head were done using a cephalostat (head-holding device). All subjects included in the study underwent a detailed clinical assessment and analyses of their dental and skeletal profiles, as well as soft tissue profiles on cephalometric radiography. The equipment used for the imaging analyses was the Rotograf Plus (20090 Buccinasco MI Italy) (Number and series: 00036045), and the CEI-OPX/105 X-ray tube (CEI, Bologna) with a protective filter ( $2.5 \mathrm{~mm}$ aluminium-equivalent). Lateral cephalometric films were taken from a distance of $165 \mathrm{~cm}$ away from the tube, using a cephalostat to ensure rigid head fixation. The subjects were placed in the cephalostat in such a way that the sagittal plane of the head was at a $90^{\circ}$ angle to the path of the X-rays. The Frankfort horizontal plane (from the lower edge of foramen orbitale and upper rim of the external auditory canal) was parallel to the ground, the teeth were in the central occlusion position, and the lips were in relaxed position. No corrections of the magnification factors were required, since all the radiographs were taken with the same equipment and the same proportions. Each cephalogram was fixed on the viewing box with the profile to the right, and the acetate tracing paper was fixed by a tape at the top. The soft tissue and skeletal features were traced manually in a darkened room, using a $0.5 \mathrm{~mm}$ lead pencil. All the image tracing was done by the main investigator. Subjects were divided into four groups. The size of the ANB angle according to Steiner and the angle inclination of the upper incisors were the criteria used to categorise the subjects in this study. The cephalometric ANB angle was the parameter that defined the sagittal relationship between the upper and lower jaw as orthognathic, distal, or mesial (Fig. 5).

The points that determined the ANB angle included, point $\mathrm{N}$, the nasion, located on the suture between the frontal and nasal bones; point $A$, the deepest point on the line between the anterior nasal spine and the prosthion (alveolar point); and point B, 
Table 1. Facial landmarks (with abbreviations) used for the determination of angular parameters

\begin{tabular}{|c|c|}
\hline Glabella (G) & $\begin{array}{l}\text { The most anterior point of the middle line } \\
\text { of the forehead }\end{array}$ \\
\hline Nasion (N) & $\begin{array}{l}\text { The point in the middle line located at the nasal } \\
\text { root }\end{array}$ \\
\hline Nasal dorsum (Nd) & The middle point the external ridge of the nose \\
\hline Pronasale (Prn) & The most prominent point of the tip of the nose \\
\hline Columella (Cm) & The most inferior and anterior point of the nose \\
\hline Subnasale (Sn) & The point where the upper lip joins the columella \\
\hline Labiale superior (Ls) & $\begin{array}{l}\text { The point that indicates the mucocutaneous } \\
\text { border of the upper lip }\end{array}$ \\
\hline Pogonion $(\mathrm{Pg})$ & The most anterior point of the chin \\
\hline
\end{tabular}

the deepest point from the line between the infradentale and the pogonion (midline of the chin).

The first group was with a eugnathic dentoskeletal relationship (class I) and the ANB angle between $2^{\circ}$ and $4^{\circ}$. The second group was with a distal dentoskeletal pattern, an ANB angle $>4^{\circ}$, and the inclination angle of the upper incisor $>22^{\circ}$ (class II, division I, or class II/1). The third group was with a distal pattern, an ANB angle $>4^{\circ}$ and the inclination angle of the upper incisors inclination $<22^{\circ}$ (class II, division 2 , or class $I / / 2$ ). The fourth group was with a mesial pattern and an ANB angle $<1^{\circ}$ (class III). Each group consisted of 30 subjects (15 males, 15 females). Since subjects with class I generally had a harmonic facial profile due to the eugnathic jaw relationship, this group was taken as the control and then compared to the other three groups.

Then, on the radiograph of each patient, the following anthropometric soft tissue points were determined (Table 1, Fig. 6).

By pulling the lines from these points, the following profile angles were formed (Fig. 7):

- nasofrontal angle (G-N-Nd) - angle between glabella $(\mathrm{G})$ to nasion $(\mathrm{N})$ line and nasion to nasal dorsum (Nd) line;

- nasofacial angle or nasal projection angle (Prn-N-Pg) - angle between nasion $(\mathrm{N})$ to pogonion line $(\mathrm{Pg})$ and nasion to tip (Prn) line;

- nasal tip angle (N-Prn-Cm) - angle between nasion (N) to tip/pronasale line (Prn) and tip to columella $(\mathrm{Cm})$ line;

- nasolabial angle (Cm-Sn-Ls) - angle between columella point $(\mathrm{Cm})$ to subnasale $(\mathrm{Sn})$ line and subnasale to labiale superior (Ls) line.

Since these were angular measures, all results were expressed in degrees $\left(^{\circ}\right)$.

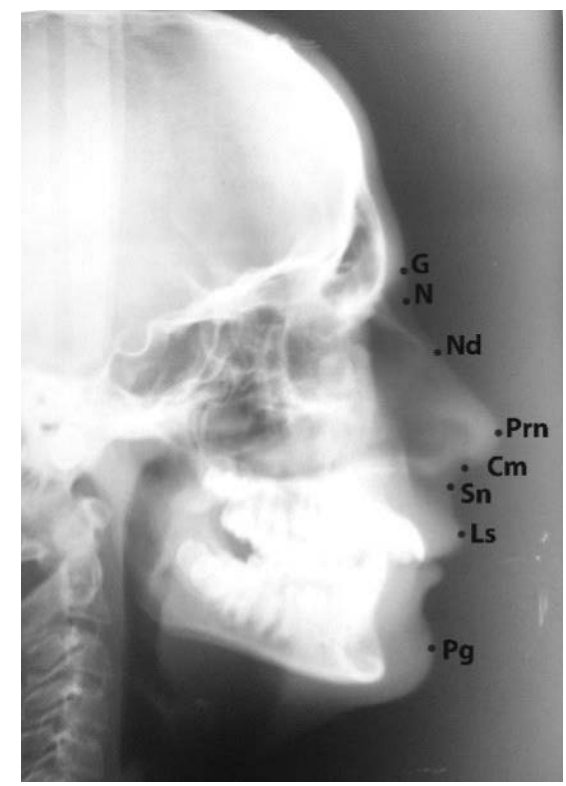

Figure 6. The landmarks used in this investigation: glabella (G), nasion (N), nasal dorsum (Nd), pronasale (Prn), columella (Cm), subnasale $(\mathrm{Sn})$, labiale superior (Ls), pogonion $(\mathrm{Pg})$.

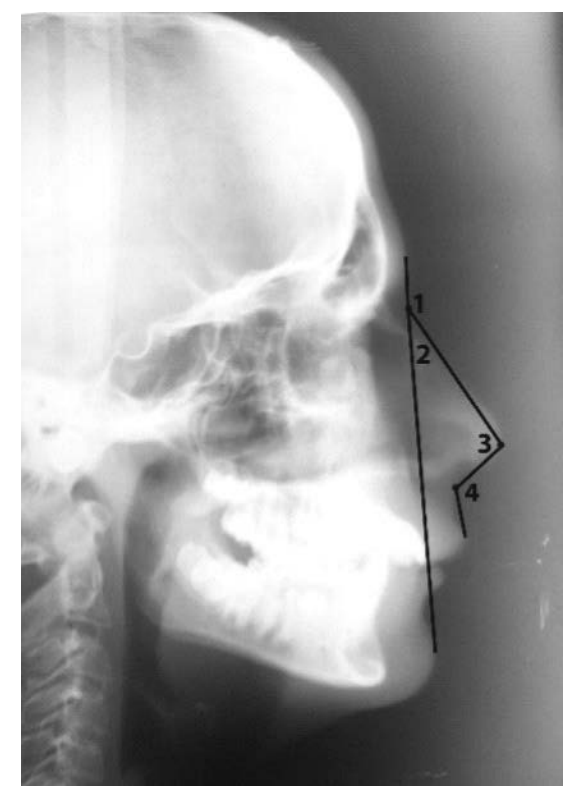

Figure 7. Angular parameters: 1 - nasofrontal angle (G-N-Nd); 2 - nasofacial angle (Prn-N-Pg); 3 - nasal tip angle (N-Prn-Cm); 4 - nasolabial angle (Cm-Sn-Ls).

\section{Statistical analysis}

Statistical analysis of obtained morphometric data was performed by IBM SPSS Statistics (version 25). Results of the Kolmogorov-Smirnov test showed that majority of the morphometric parameters were not normally distributed. Consequently, significance of detected differences was evaluated by non-parametric Mann-Whitney U test. 
Table 2. Descriptive statistics for class I, class II division 1, class II division 2 and class III

\begin{tabular}{lcccc}
\hline & Class I & Class II/1 & Class II/2 & Class III \\
\hline G-N-Nd & $138.80 \pm 9.39$ & $138.50 \pm 9.91$ & $138.70 \pm 6.63$ & $134.23 \pm 12.58$ \\
& $117.0-153.0$ & $111.0-152.0$ & $121.0-148.0$ & $110.0-160.0$ \\
Prn-N-Pg & $29.63 \pm 3.61$ & $33.13 \pm 4.61$ & $31.00 \pm 4.16$ & $26.07 \pm 4.08$ \\
& $25.0-39.0$ & $26.0-47.0$ & $23.0-38.0$ & $20.0-35.0$ \\
N-Prn-Cm & $91.00 \pm 5.39$ & $88.87 \pm 6.28$ & $86.57 \pm 11.15$ & $86.20 \pm 8.21$ \\
& $79.0-98.0$ & $75.0-102.0$ & $60.0-108.0$ & $72.0-114.0$ \\
Cm-Sn-Ls & $111.67 \pm 10.76$ & $114.30 \pm 8.56$ & $111.37 \pm 14.3$ & $106.47 \pm 10.94$ \\
& $90.0-130.0$ & $92.0-133.0$ & $80.0-135.0$ & $86.0-132.0$ \\
\hline
\end{tabular}

Data are shown as mean value \pm standard deviation and minimum-maximum.

Table 3. Statistical differences between class I and other groups

\begin{tabular}{lccc}
\hline Z value; P - probability value & I-II/1 & I-II/2 & I-III \\
\hline G-N-Nd - Z; P & $-0.044 ; 0.965$ & $-0.333 ; 0.739$ & $-1.480 ; 0.139$ \\
Prn-N-Pg - Z; P & $-3.162 ; 0.002^{* *}$ & $-1.577 ; 0.115$ & $-3.401 ; 0.001^{* * *}$ \\
N-Prn-Cm -Z; P & $-1.704 ; 0.088$ & $-2.201 ; 0.028^{* *}$ & $-3.132 ; 0.002^{* *}$ \\
Cm-Sn-Ls -Z;P & $-1.030 ; 0.303$ & $-0.163 ; 0.871$ & $-1.701 ; 0.089$ \\
\hline
\end{tabular}

**Highly significant $0.01 \geq p>0.001 ;{ }^{* * *}$ Very highly significant $p \leq 0.001$

In the statistical assessment, the following levels of significance were used: not significant $p>0.05$; significant $0.05 \geq \mathrm{p}>0.01\left(^{*}\right)$; highly significant $0.01 \geq p>0.001\left(^{* *}\right)$; very highly significant $\mathrm{p} \leq 0.001\left({ }^{* *}\right) ; \mathrm{p}=$ probability value.

\section{RESULTS}

Descriptive statistics of average angular values for different parameters in four groups with different dentoskletal pattern (class I, class II/1, class II/2, class III) were shown in Table 2 . The statistical differences of average values of the examined angles between the group with class I and the other three groups were shown in Table 3:

- nasofrontal angle: the average value for subjects in current study with class I was $138.80 \pm 9.39^{\circ}$, that was similar to other groups without significant differences;

- nasofacial angle: the average value for subjects with class I was $29.63 \pm 3.61^{\circ}$, and for the group with class II/1 $\left(33.13 \pm 4.61^{\circ}\right)$ that's significantly higher. Average value in the group with class III $\left(26.07 \pm 4.08^{\circ}\right)$ that's significantly lower related $^{2}$ to the control group;

- nasal tip angle: the average value for subjects with class I was $91 \pm 5.39^{\circ}$. Significant differences were established by comparing class I and class II/2, so as class I and III subjects;

- nasolabial angle: the average value of this angle in subjects with class I was $111.67 \pm 10.76^{\circ}$. There were no significant differences between the subjects with class I and other patterns.

\section{DISCUSSION}

Protrusion or retrusion of midfacial (nasal) segment influences the facial aesthetics and can be objectively determined by measuring the facial angles of this segment. Protrusion of this segment is racially characteristic for Africans, retrusion for Asians [6, 11, 17]. In Caucasians, retrusion of nasal third is rarely connected to normal racial anthropological variations. It is the consequence of dentofacial deformity or existence of adenoid face. In case of adenoid face, middle third of the face is short and depressed with nose that undeveloped in all three dimensions. External physiognomy of the nose is divided into its component, aesthetic parts.

The nasofrontal angle is more open in females than in males, revealing a less convex nasal radix [16]. It demonstrates a higher nasal tip rotation in females, which is considered aesthetically favourable $[4,7,8$, 20]. According to various authors, in Caucasian eugnathic subjects, it has a value of $132.39 \pm 8.015^{\circ}$ [1], $133.16 \pm 8.88^{\circ}[32], 137.13 \pm 7.98^{\circ}[5]$, to $139.1 \pm$ $\pm 6.35^{\circ}$ [3], that's similar to mean values in the current study (Table 2). The nasofrontal angle is independent of the sagittal dentoskeletal pattern as indicated by these results. Based on reported results, among members of different races, there are higher differences 
in values of nasofrontal angle than among subjects with different pattern. Results indicate large standard deviations and a large degree of individual variability. Accordingly, comparisons should be performed with the range of normal values not mean values.

The nasofacial angle indicates its prominence in relation to the entire facial massif [6]. The average values for eugnathic subjects range, according to various authors, from $30^{\circ}$ to $40.5^{\circ}[3,8,20]$. In the current study, for subjects with class I it is $29.63 \pm$ $\pm 3.61^{\circ}$, being lower than values published by other authors. This value is significantly lower than average in the group with class II/1 and higher than average in the group with class III (Tables 2, 3). The result was the effect of the pogonion point position. The pogonion has an anterior position in subjects with class III, thus reducing the nose projection in relation to the $\mathrm{N}-\mathrm{Pg}$ line. On the other hand, in subjects with class II/1, the distal pogonion projection, due to posterior mandible position, leads to a larger projection of the nose tip in relation to the N-Pg line. Because of this finding, it would be better if this angle was reduced at class II division 1, so distal position of mandible can be camouflaged. On the other hand, it would be better if that angle was increased at class III, so domination of mandible is camouflaged. Insignificant differences were found in values of this angle between the group with class I and class II/2, since the pogonion position of both groups, due to the specific skeletal pattern of this class, is similar to the one with class I. Fortes et al. [10] by comparing this angle to Caucasian subjects with pleasant and unpleasant facial profiles, found the values of $32.73 \pm 2.77^{\circ}$ for pleasant facial profiles and the values of $33.43 \pm 3.01^{\circ}$ for unpleasant facial profiles. The difference is statistically insignificant. Accordingly, the aesthetic impression is not affected by the value of the nasal projection angle [10].

The average value of the nasal tip angle in the Caucasian eugnathic subjects is $70.1^{\circ}$ to $84.3^{\circ}$ $[1,3,5,20,31,32]$, in the current study $91 \pm 5.39^{\circ}$, indicating higher values compared to subjects from other reference studies. Significant differences were established by comparing class I and class II/2, so as class I and III (Table 3). Mentioned differences in the nose tip angle between class I and class II/2 may be explained by a specific nose tip in subjects with this dentoskeletal pattern. A smaller nose tip angle characterizes these subjects, therefore the tip of the nose has a tendency of convergence with the chin, being a frequent characteristic class II/2 [23]. Subjects with class III are found to have a significantly smaller nose tip angle thus indicating a compensatory tendency of the nose tip to mask the skeletal discrepancy. Consequently the nasomaxillary complex is positioned more posterior in relation to the lower jaw. The sharper nasal tip (reduced nose tip angle) is responsible for the reduced nasolabial angle $[4,5,21]$.

The nasolabial angle is important in the assessment of the relationship between the nasal base and the upper lip. It is a strategic part of the facial profile. Burstone defines the nasolabial angle as a representation of the maxilla inclination - when increased, this angle represents the maxillary retroclination, and when decreased, it represents the maxillary proclination [9]. Some authors consider this angle to be of great clinical importance with its size depending on the anteroposterior position and the inclination of the upper incisors respectively [21]. Other authors believe that analyses of this angle can't provide the answer which segment of the nasomaxillary complex causes the problem. Therefore identification of the exact cause of decreasing the nasolabial angle is difficult to achieve. This angle is formed of two lines, one from the base of the nose, and the other from the upper lip. They are independent as the measurement of this angle does not reveal the component responsible for its variability. It could be either a nose or a lip, or both $[9,10]$. It is believed that the larger angle is aesthetically more favourable for women, whereas the sharper one for men $[13,19,25,27]$. The average value of this angle in subjects of current study with class I is $111.67 \pm 10.76^{\circ}$. In other studies performed on the Caucasian eugnathic subjects, slightly lower values were obtained: Ballin et al. [5] in Brazilian Caucasian $105.41 \pm 10.66^{\circ}$ [5], Anić-Milošević et al. [3] for males $105.49^{\circ}$ and for females $109.78^{\circ}$, Lapter-Varga et al. [14] 106.39 , Uysal et al. [30] for males $102.9 \pm 10.5^{\circ}$, for females $107.7 \pm 8.6^{\circ}$ in Turkey and for Caucasian North American $112.6 \pm$ $\pm 10.6^{\circ}$ for males and $111.1 \pm 9.7^{\circ}$ for females, being close to the average values of nasolabial angle in our sample. Fortes et al. [10] when comparing this angle with Caucasian subjects, found the following average values: $104.37 \pm 7.25^{\circ}$ for pleasant facial profiles and $104.53 \pm 12.91^{\circ}$ for unpleasant facial profiles. The difference is statistically insignificant.

In the current study the values of the nasolabial angle in subjects with different patterns are approximate, with insignificant differences (Table 3). The result is unexpected since different dentoskeletal pat- 
terns indicate different projections of the nasomaxillary complex. Consequently, thickness of the upper lip compensates the development of the nasomaxillary complex, which most likely masks skeletal discrepancy and maintains an angle relationship with columella $[25,27]$, making insignificant the established differences on our sample.

During forensic facial reconstruction based on the skull, as the most defined angles were determined nasofrontal and nasolabial angle. These angles, with knowing average thickness of the soft tissues on specific places, are possible to determine with a lot of accuracy. However, when it comes to the nose tip angle and the nasofacial angle we need to take into consideration dentoskeletal pattern because the values of these angles are conditioned with the dentoskeletal class, which is established in the current study.

\section{CONCLUSIONS}

By comparing the average values of the profile angles of the midfacial segment, it was established that the nasal tip angle is significantly lower in subjects with class II division 2 as well as class III. The nasofacial angle was significantly higher in subjects with class II division 1 and significantly lower with class III. The frontonasal and nasolabial angle were independent of the sagittal dentoskeletal pattern.

\section{Conflict of interest: None declared}

\section{REFERENCES}

1. Akter $L$, Hossain M. Angular photogrammetric soft tissue facial profile analysis of Bangladeshi young adults. APOS Trends Orthod. 2017; 7: 279-286, doi: 10.4103/23211407.219434.

2. Al Taki A, Guidoum A. Facial profile preferences, self-awareness and perception among groups of people in the United Arab Emirates. J Orthod Sci. 2014; 3(2): 55-61, doi: 10.4103/2278-0203.132921, indexed in Pubmed: 24987664.

3. Anić-Milosević S, Lapter-Varga M, Slaj M. Analysis of the soft tissue facial profile by means of angular measurements. Eur J Orthod. 2008; 30(2): 135-140, doi: 10.1093/ ejo/cjm116, indexed in Pubmed: 18263886.

4. Armijo BS, Brown M, Guyuron B. Defining the ideal nasolabial angle. Plast Reconstr Surg. 2012; 129(3): 759-764, doi: 10.1097/PRS.0b013e3182402e12, indexed in Pubmed: 22090249.

5. Ballin AC, Carvalho B, Dolci JE, et al. Anthropometric study of the caucasian nose in the city of Curitiba: relevance of population evaluation. Braz J Otorhinolaryngol. 2018; 84(4): 486-493, doi: 10.1016/j.bjorl.2017.06.004, indexed in Pubmed: 28728950.
6. Diomande M, Beugre JB, Koueita MK, et al. Relationship between Angular Measurements and Facial Shape of Young Ivorians with Normal Dental Occlusion. Sci World J. 2018; 2018: 6395910, doi: 10.1155/2018/6395910, indexed in Pubmed: 29681778.

7. El-Hadidy M, El-Din AB, El-Bassioni L, et al. Cephalometric analysis for evaluating the profile nasal morphology in egyptian adults. J Plast Reconstr Surg. 2007; 31(2): 243-249.

8. Ezeuko V, Eboigbe P. Angular photogrammetric analysis of the facial profile of the adults of Bini ethnicity of Nigeria. Ann Bioanthropol. 2015; 3(1): 14-17, doi: 10.4103/23157992.160737.

9. Fitzgerald J, Nanda R, Currier G. An evaluation of the nasolabial angle and the relative inclinations of the nose and upper lip. Am J Orthod Dentofac Orthop. 1992; 102(4): 328-334, doi: 10.1016/0889-5406(92)70048-f.

10. Fortes HN, Guimarães TC, Belo IM, et al. Photometric analysis of esthetically pleasant and unpleasant facial profile. Dental Press J Orthod. 2014; 19(2): 66-75, doi: 10.1590/2176-9451.19.2.066-075.oar, indexed in Pubmed: 24945516 .

11. Darkwah W, Kadri A, Adormaa B, et al. Cephalometric study of the relationship between facial morphology and ethnicity: Review article. Trans Res Anat. 2018; 12: 20-24, doi: 10.1016/j.tria.2018.07.001.

12. Hamid S, Abuaffan AH. Facial soft tissue thickness in a sample of Sudanese adults with different occlusions. Forensic Sci Int. 2016; 266: 209-214, doi: 10.1016/j. forsciint.2016.05.018, indexed in Pubmed: 27314547.

13. Kim SY, Bayome M, Park JH, et al. Evaluation of the facial dimensions of young adult women with a preferred facial appearance. Korean J Orthod. 2015; 45(5): 253-260, doi: 10.4041/kjod.2015.45.5.253, indexed in Pubmed: 26445720.

14. Lapter-Varga M, Anić Milosević S, Vusić A, et al. Soft tissue facial profile of normal dental and skeletal subjects in Croatian population aged 12 to 15 years. Coll Antropol. 2008; 32(2): 523-528, indexed in Pubmed: 18756905.

15. Lazović DG. Analysis of anatomical and morphological characteristics of the nasal pyramid as a criterion for approach selection in rhinoplasty. Dissertation. University of Belgrade, 2016.

16. Letort-Mena JJ, Astudillo-Molina JM, Pedroza-Campo F, et al. Anthropometric measures of nasal pyramid in young people Ecuadorians and their cosmetic preferences. Acta otorrinolaringologica cir. Cabezacuello. 2018; 46(1): 39-45, doi: 10.37076/acorl.v46i1.98.

17. Müller G. Kiefer-Gebiß-Anomalien und Rasse. Fortschritte der Kieferorthopädie. 1965; 26(2): 101-145, doi: 10.1007/ bf02163502.

18. Nondumiso YHM. Soft tissue facial profile assessment of 15-20 year old Tswana subjects. MSD thesis, University of Pretoria, 2009.

19. Pandian KS, Krishnan S, Kumar SA. Angular photogrammetric analysis of the soft-tissue facial profile of Indian adults. Indian J Dent Res. 2018; 29(2): 137-143, doi: 10.4103/ijdr.IJDR_496_16, indexed in Pubmed: 29652003.

20. Peck G, Michelson L. Anatomy of aesthetic surgery of the nose. Clin Plastic Surg. 1987; 14(4): 737-748, doi: 10.1016/s0094-1298(20)31499-1. 
21. Perkins $K$, Shah $A$, Patel $A$, et al. The effect of nasal tip rotation on upper lip length. Aesthet Surg J. 2017; 37(5): 504-510, doi: 10.1093/asj/sjw234, indexed in Pubmed: 28034843.

22. Perovic T. Facial Profile - Harmony and Aesthetic. LAP LAMBERT Academic Publishing. Saarbrücken, Germany 2019.

23. Perović T. Class II/2 malocclusions and the face profile harmony. Med Sci Monit. 2017; 23: 5589-5598, doi: $10.12659 / \mathrm{msm} .905453$.

24. Reis S, Abrão J, Filho LC, et al. Estudo comparativo do perfil facial de indivíduos Padrões I, II e III portadores de selamento labial passivo. Revista Dental Press de Ortodontia e Ortopedia Facial. 2006; 11(4): 36-45, doi: 10.1590/ s1415-54192006000400005.

25. Santos R, Ruellas A. Dentofacial characteristics of patients with Angle Class I and Class II malocclusions. Dental Press J Orthod. 2012; 17(2): 46.e1-46.e7, doi: 10.1590/s217694512012000200010.

26. Schulze Ch. Lehrbuch für Kieferorthopadie. Buch- und Zeitschriftenverl [in Germany]. Die Quintessenz Bibliothek, Berlin 1993.

27. Tanić T, Blažej Z, Mitić V. [Soft tissue thickness of face profile conditioning by dento-skeletal anomalies]. Srp Arh Celok Lek. 2011; 139(7-8): 439-445, doi: 10.2298/ sarh1108439t, indexed in Pubmed: 21980651.

28. Traldi A, Valdrighi HC, de Souza LZ, et al. Evaluation of facial morphology and sagittal relationship between dental arches in primary and mixed dentition. Dental Press J Orthod. 2015; 20(4): 63-67, doi: 10.1590/21769451.20.4.063-067.oar, indexed in Pubmed: 26352847.

29. Umale W, Singh K, Azam A, et al. Evaluation of horizontal lip position in adults with different skeletal patterns: a cephalometric study. J Oral Health Craniofac Sci. 2017; 2(1): 009-016, doi: 10.29328/journal.johcs.1001005.

30. Uysal T, Baysal A, Yagci A, et al. Ethnic differences in the soft tissue profiles of Turkish and European-American young adults with normal occlusions and well-balanced faces. Eur J Orthod. 2012; 34(3): 296-301, doi: 10.1093/ ejo/cjq165, indexed in Pubmed: 21273287.

31. Uzun A, Akbas $H$, Bilgic $S$, et al. The average values of the nasal anthropometric measurements in 108 young Turkish males. Auris Nasus Larynx. 2006; 33(1): 31-35, doi: 10.1016/j.anl.2005.05.004, indexed in Pubmed: 16039817.

32. Uzun A, Ozdemir F. [Morphometric analysis of nasal shapes and angles in young adults]. Braz J Otorhinolaryngol. 2014; 80(5): 397-402, doi: 10.1016/j.bjorl.2014.07.010, indexed in Pubmed: 25303814.

33. Wen YiF, Wong HM, Lin R, et al. Inter-Ethnic/Racial facial variations: a systematic review and Bayesian meta-analysis of photogrammetric studies. PLoS One. 2015; 10(8): e0134525, doi: 10.1371/journal.pone.0134525, indexed in Pubmed: 26247212. 